\title{
TITLE:
}

\section{$<$ News $>$ A New Code of Observation Employed at Mahale: Prevention against a Flu-like Disease}

\section{AUTHOR(S):}

Hanamura, Shunkichi; Kiyono, Mieko; Nakamura, Michio; Sakamaki, Tetsuya; Itoh, Noriko; Zamma, Koichiro; Kitopeni, Rashidi; Matumula, Moshi; Nishida, Toshisada

\section{CITATION:}

Hanamura, Shunkichi ...[et al]. <News> A New Code of Observation Employed at Mahale: Prevention against a Flu-like Disease. Pan Africa News 2006, 13(2): 13-16

\section{ISSUE DATE:}

2006-12

URL:

http://hdl.handle.net/2433/143469

RIGHT:

Copyright (C) Pan Africa News. 


\section{<NEWS>}

A New Code of Observation Employed at Mahale: Prevention against a Flu-like Disease

Shunkichi Hanamura', Mieko Kiyono', Michio Nakamura ${ }^{1}$, Tetsuya Sakamaki, Noriko Itoh ${ }^{1}$, Koichiro Zamma ${ }^{2}$,
Rashidi Kitopeni, Moshi Matumula ${ }^{3}$,
and Toshisada Nishida ${ }^{2}$

${ }^{1}$ Graduate School of Science, Kyoto University 2Japan Monkey Centre ${ }^{3}$ Mahale Mts. Chimpanzee Research Project

Reports have indicated that many chimpanzees have died from infectious diseases such as a flu-like epidemic, poliomyelitis and Ebola in the natural habitat1, 2, 3, 4, 5. From June to July 


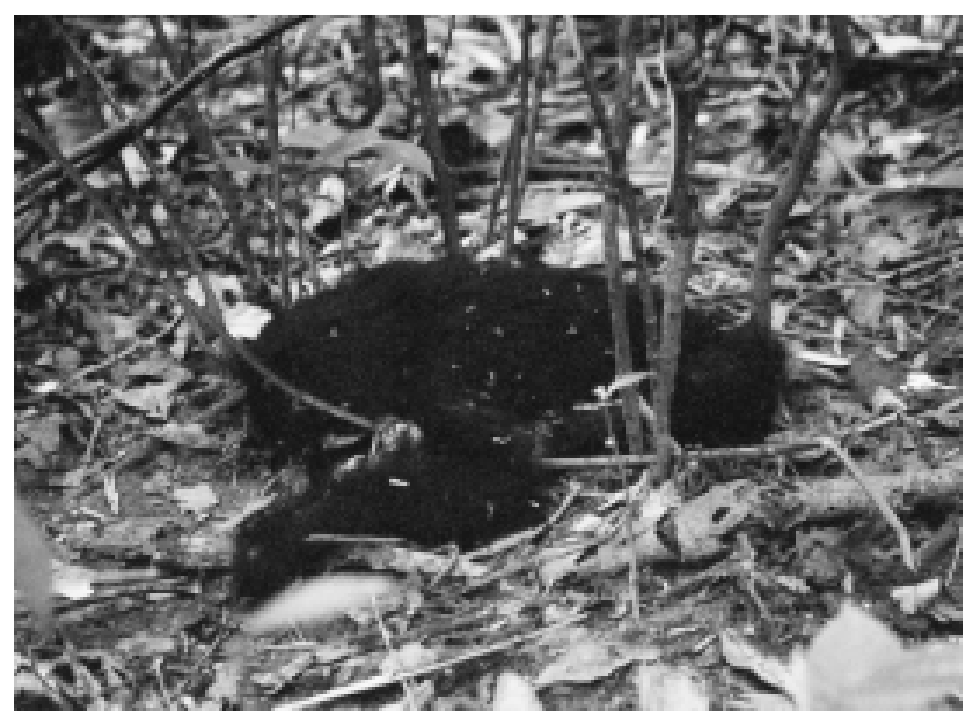

Fig. 1. Dead body of an infant Rhea found in the bush two or three days after her death still grasping the vine with the right hand and holding a dead branch with the left one.

2006, we observed an outbreak of a flu-like disease among the chimpanzees of the Mahale $M$ group. No chimpanzee showed any symptom of disease in May 2006. However, an adult male was first confirmed to cough on J une 3, 2006. Within a few days, an adult female and two adult males including the alpha male also began to cough. Subsequently, at least 23 individuals showed symptoms such as coughing, sniveling, and crouching on the ground. This means that $35.4 \%$ of the entire M Group (65 before the outbreak) suffered from the disease. In the latter half of $J$ uly, the number of individuals showing symptoms decreased, and the disease had almost ceased by the end of J uly.

We confirmed the deaths of three infants who all had suffered from the disease. We found the corpse of one of them on J une 26, 2006 (Rhea, Fig. 1) and observed the corpses of two other infants carried by their mothers on J uly 1 and J uly 15, 2006. In addition to them, nine chimpanzees disappeared during this period and they have not been seen at the time of writing (November 30, 2006). The inference of their deaths were supported by the fact that we recovered another corpse of an adult female (Fig. 2) and the upper part of the cranium and the whole left scapula of a juvenile male (Fig. 3). Therefore, a total of 12 chimpanzees likely died of disease. We will report this outbreak in detail soon (Hanamura et al. in

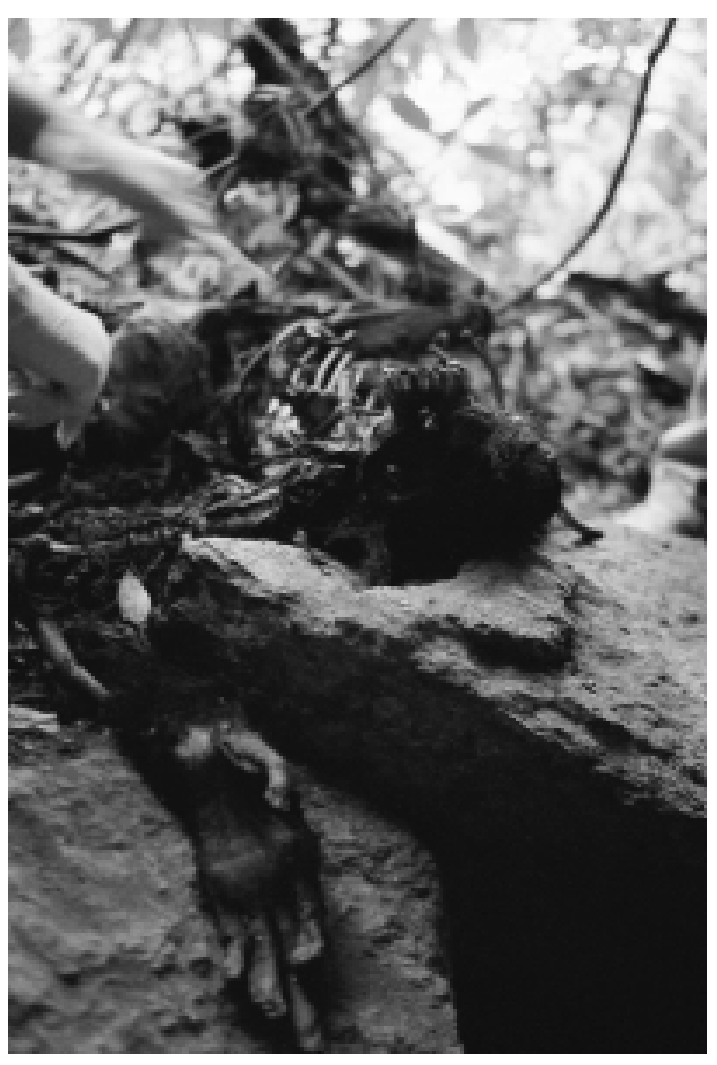

Fig. 2. Dead body of an adult female found in the bush on 29 June 2006 eaten by a bushpig or similar animal.

prep.). The possible victims include an adult male, 3 adult females, a juvenile male, and 7 infants. This was comparable to the loss of 11 chimpanzees due to the outbreak of a fluelike disease that occurred in 19932.

Since it is possible that these epidemics were caused by the increased contact with humans, we felt it an urgent issue to explore the appropriate ways of observing chimpanzees both by researchers and tourists. There had al ready been some guidelines or rules for observing chimpanzees proposed by MWCS and later by the Park as a result of establishing the General Management Plan (GMP) for MMNP. However, these guidelines had been poorly announced to tourists and thus not applied before the outbreak. In addition, although the distances from chimpanzees are set in GMP as $10 \mathrm{~m}$ for tourists and $7.5 \mathrm{~m}$ for researchers, it is often difficult to rigidly maintain these distances. This is because chimpanzees themselves sometimes come closer to humans and because humans unconsciously approach chimpanzees when they are in a dense 


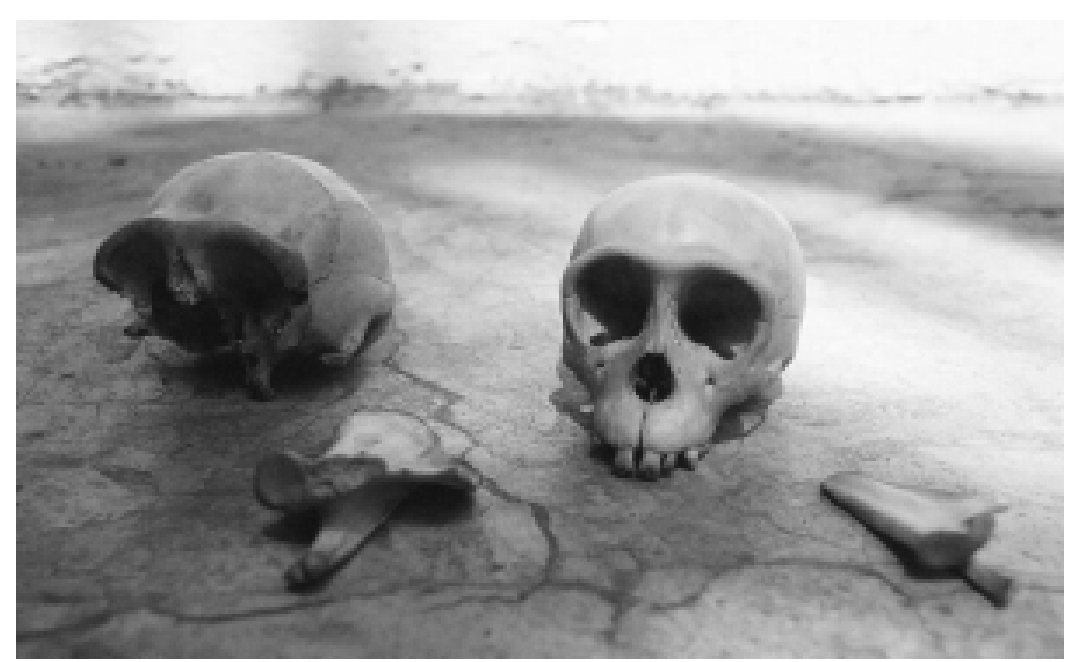

Fig. 3. Upper part of cranium and left scapula found on July 32006 (left). Rhea's cranium and scapula (right) are shown for comparison of the sizes.

Kigoma. This quarantine has been complied by Gombe re searchers and filmmakers.

Fortunately, everybody is now willing to wear masks. Also, as a result of the cooperation of tour operators, veterinarians, park staff and researchers, the regulations on chimpanzee viewing established by TANAPA, such as the distance of observation, duration of observation, the number of tourists per group and tourist groups per day, and the prohibittion against more than two tourist group observing the same party of chimpanzees at the same

bush. It is also difficult for some guides to persuade tourists to keep distance. In addition, we see it problematic that tourists often go off the observation trails which made it more difficult for them to keep distance from chimpanzees.

Thus we decided to introduce a new code of observation: the application of face masks for everybody who observes the $M$ group chimpanzees. This can at least reduce the risk of droplet infection from humans and has already been employed by Taï researchers. Some of the authors were just leaving J apan for Mahale when the epidemic came to an end. They carried face masks from J apan to Mahale. The purchase of those face masks was financially supported by MWCS. We provided the masks to all the tourist companies in the park, the park staff and the research assistants, and asked them to wear the masks whenever they observe the $M$ group chimpanzees (Fig. 4). We also made and distributed a leaflet explaining to tourists why they were requested to wear the masks. The used masks were collected and burnt by tour operators after returning to the camp. Although there is some skepticism about the effectiveness of the face mask $^{6}$, it is surely better than nothing when we consider its effectiveness in reducing the likeliness of transmission of virus between humans.

Researchers also began to voluntarily carry out a one-week quarantine before observing chimpanzees after we arrived at the nearest town time, are now being more rigidly applied than before the outbreak, although they are still not completely followed. We need continuous efforts for full application of the regulations in order to minimize the risk of epidemic outbreak among groups of chimpanzees habituated for the purpose of research and/or tourism. For that

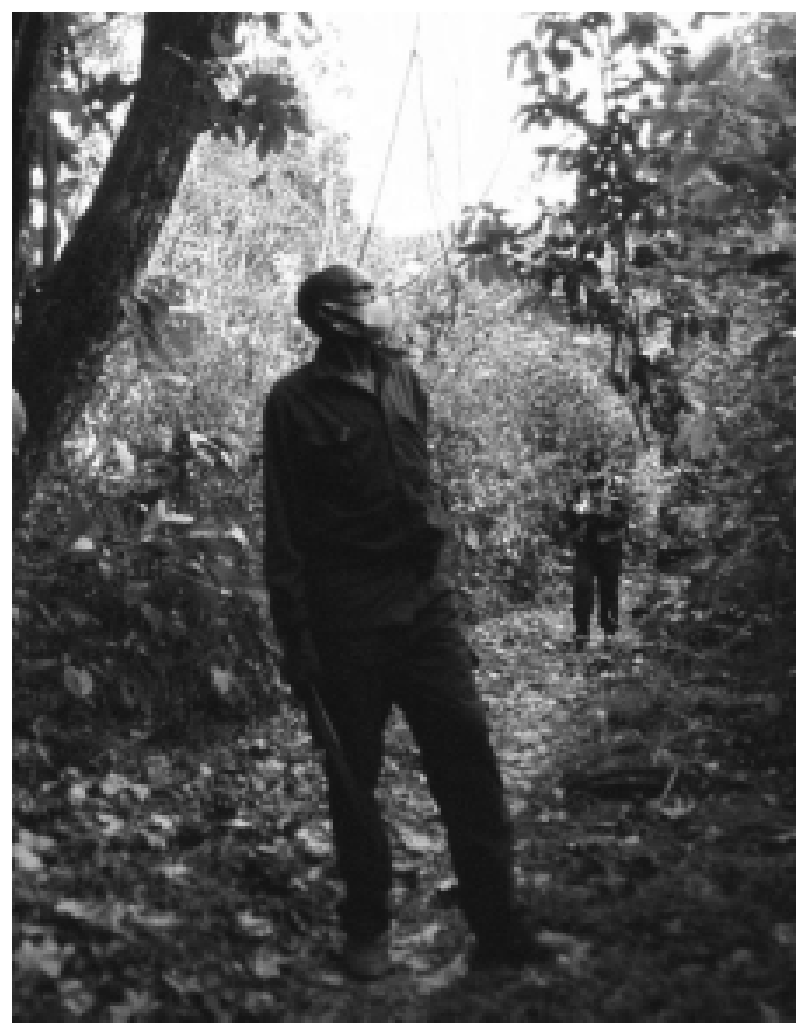

Fig. 4. Research assistants wearing face masks. We wear face masks whenever we observe the $M$ group chimpanzees at Mahale. 
purpose, it is essential that researchers, veterinarians, tour operators, and park staff cooperate even more.

We thank COSTECH, TAWIRI, TANAPA, MMNP, and MMWRC for permitting us to conduct research at Mahale. Dr. Magdalena Lukasik-Braum and Dr. Titus Mlengeya of TANAPA provided much support and advice. This study was financially supported by MEXT (16255007 to TN and 16770186 to MN) and Global Environment Research Fund F-061.

\section{REFERENCES}

1. Nishida T, Takasaki H, Takahata Y 1990. Demography and reproductive profiles. In: The chimpanzees of the Mahale Mountains, Nishida T (ed), University of Tokyo Press, pp. 63-98.

2. Hosaka K 1995. Epidemics and wild chimpanzee study groups. Mahale: A single flu epidemic killed at least 11 chimpanzees. Pan Afr News 2(2): 3-4.

3. Nishida $T$, Corp $N$, Hamai $M$, Hasegawa $T$, Hiraiwa-Hasegawa M, Hosaka K, Hunt KD, Itoh N, Kawanaka K, Matsumoto-Oda A, Mitani JC, Nakamura M, Norikoshi K, Sakamaki T, Turner L, Uehara S, Zamma K 2003. Demography, female life history, and reproductive profiles among the chimpanzees of Mahale. AmJ Primato/ 59: 99-121.

4. Lonsdorf EV, Travis D, Pusey AE, Goodall J 2006. Using retrospective health data from the Gombe chimpanzee study to inform future monitoring efforts. AmJ Primatol 68: 897-908.

5. Boesch C, Boesch-Achermann H 1995. Taï chimpanzees confronted with a fatal Ebola virus. Pan Afr News 2(2): 2-3.

6. Walpole M 2004. An assessment of tourism in Mahale Mountains National Park, Tanzania. Report on behalf of TANAPA and FZS. 